\title{
Simulations of Australian extreme rainfall and circulation during the January 2011 La Niña
}

\author{
J. Whelan ${ }^{1} \quad$ J. S. Frederiksen ${ }^{2}$
}

(Received 27 February 2015; revised 18 November 2015)

\begin{abstract}
We examine the synoptics and the role of different classes of dynamical disturbances, from both observations and ensemble simulations, during of one of Australia's most severe flooding events in January 2011. We analyse ensemble simulations using the CSIRO Mk3L general circulation spectral model. Using wavenumber extraction techniques and dynamical mode analyses, we note the collision and convective coupling of Kelvin waves and the Madden-Julian oscillation in the Australian monsoonal region. Model simulations and the dynamical analyses are consistent with the synoptic situation, and provide a more complete explanation for the extensive precipitation impacts over Australia during January 2011.
\end{abstract}

http://journal . austms.org.au/ojs/index.php/ANZIAMJ/article/view/9353 gives this article, (C) Austral. Mathematical Soc. 2015. Published December 23, 2015, as part of the Proceedings of the 17th Biennial Computational Techniques and Applications Conference. ISSN 1446-8735. (Print two pages per sheet of paper.) Copies of this article must not be made otherwise available on the internet; instead link directly to this URL for this article. 


\section{Contents}

1 Introduction

C180

2 Australian synoptic conditions in January 2011

C181

3 Collision of equatorially-trapped waves

C184

3.1 Wavenumber-frequency filtering . . . . . . . . . . . C184

3.2 Dynamical Modes . . . . . . . . . . . . . . . . . C185

4 Mk3L ensemble simulations

C186

5 Conclusions

C191

References

C191

\section{Introduction}

El Niño Southern Oscillation (ENSO) is a coupled ocean-atmosphere phenomenon that causes major shifts in regional weather patterns on seasonal to multi-year time scales [11]. Australian climate is highly impacted by ENSO [13]. While extensive research has been conducted on ENSO, very little work focusses on the southern hemisphere, La Niña phases, or Australia specifically [11]. Frederiksen and Frederiksen [8] studied the causes of the southern Australian drought of 1997-2006 (extending to 2009) associated with some medium to strong El Niño events in terms of changes in dynamical modes. In the first dynamical mode analysis of La Niña, Whelan et al. [15] found explosive growth rates and anomalous activity in several classes of dynamical modes during January 2011. In this article we build on those results with additional wave analysis techniques on observational and numerical simulation data, as well as with ensemble simulations of the study period.

We first examine the synoptic conditions around Australia during La Niña. 
Section 2 analyses the Australian weather conditions during 2011. Observational data is used in a wavenumber-frequency filtering method to examine the locations and convective coupling of different classes of waves over Australia at the time. Section 3 summarises techniques for extracting equatorial waves and looking at growth rates of different classes of dynamical modes. Complementing these analyses is an ensemble of simulations using the Mk3L spectral general circulation model forced by observed sea surface temperatures (SSTs) and $\mathrm{CO}_{2}$. The same clases of waves are seen in the numerical simulations. These results agree with previous findings of Whelan et al. [15] in terms of active classes of modes and their unusually strong growth rates during January 2011. Section 4 presents the ensemble simulations.

\section{Australian synoptic conditions in January 2011}

While few La Niña periods are exactly the same, there are three major synoptic differences seen over Australia on comparing La Niña periods with both neutral and El Niño periods:

- high pressure systems over Australia are displaced southward (or replaced) by low pressure systems;

- tropical westerly winds from the Indian Ocean increase in strength and are drawn southeastward over north and eastern Australia by the low pressure systems;

- a series of blocking high pressure systems in the Tasman Sea stall precipitation over land for longer.

Along with strong displays of these three conditions, the 2010-2011 La Niña featured record Southern Oscillation Index values and a strongly negative Indian Ocean Dipole with record high SsTs, resulting in Australia's wettest 
Figure 1: The $700 \mathrm{mb}$ geopotential height anomaly in January 2011, an extreme example of the low pressure systems seen during La Niñas.

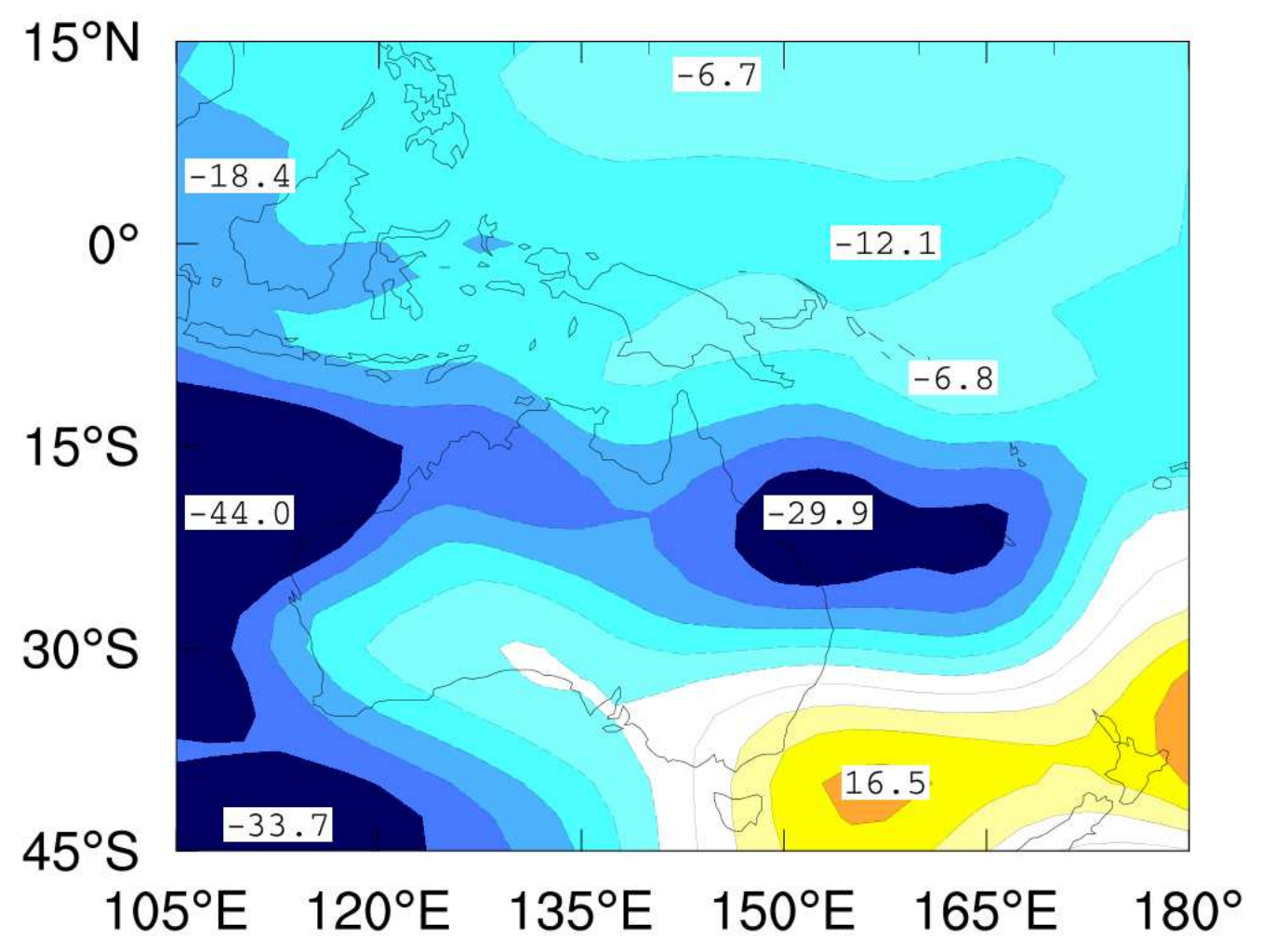

two-year period on record and monthly and daily precipitation records broken throughout the continent [1].

The most severe flooding occurred in mid-January 2011. Figure 1 shows the low pressure anomalies during January 2011 and Figure 2 shows total precipitation levels from the Australian Water Availability Project station daily precipitation data for January 9-13, the period with the most intense flooding [9]. The system reached southeast Queensland and northeast New South Wales by January 10, with daily precipitation totals reaching over 
Figure 2: Precipitation totals ( $\mathrm{mm}$ ) for January 9-13, the days of the most intense flooding, from the Australian Water Availability Project station daily precipitation data [9].

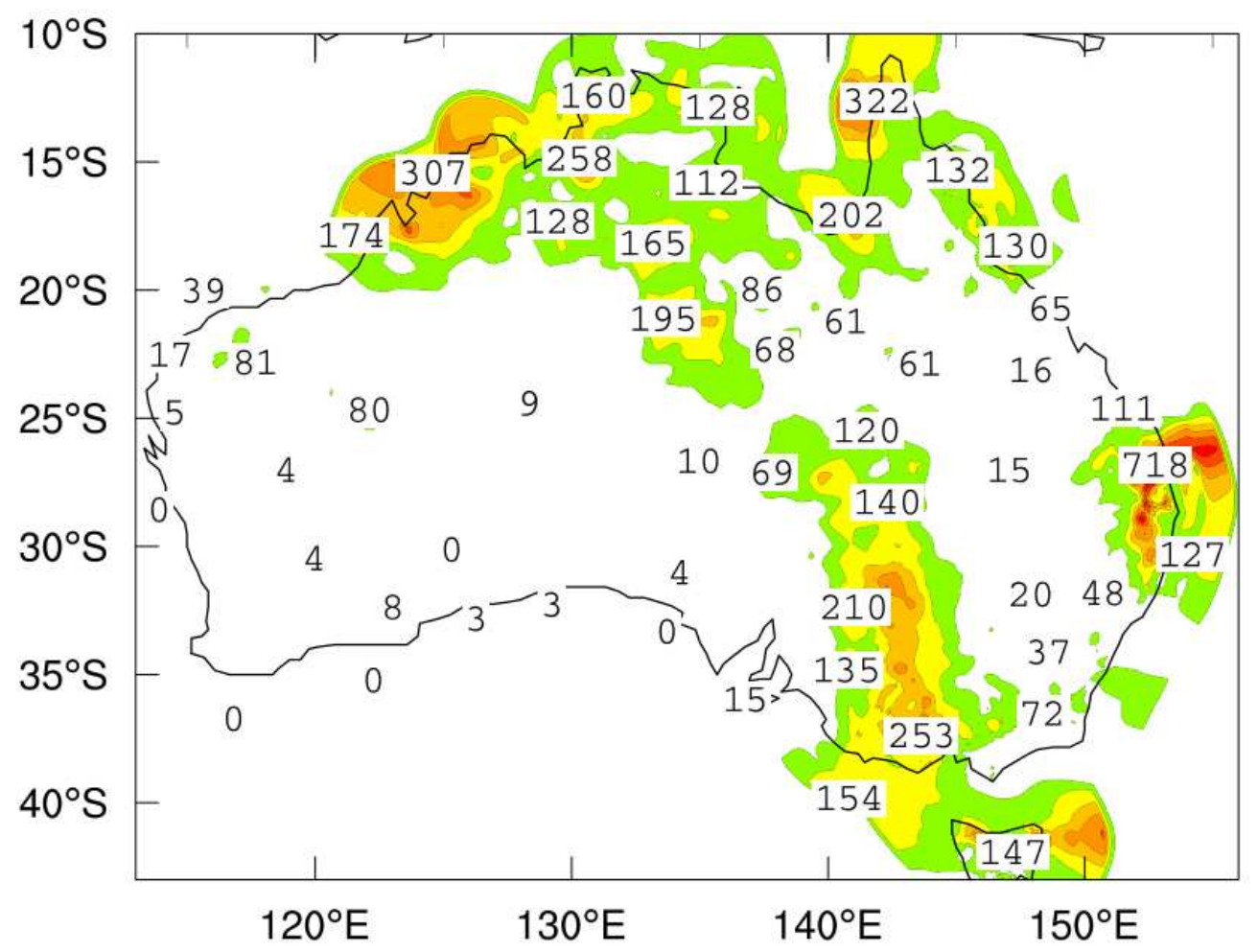

$250 \mathrm{~mm}$ at several stations in southern Queensland. Victoria received its entire summer average rainfall in the six days of January 9-14, due to tropical moisture being pulled south into a trough held in place over Victoria by blocking high pressure systems south of Tasmania. The strongly negative Indian Ocean Dipole decayed in November 2010 but left record-breaking SSTs around Australia which made available more atmospheric moisture, contributing to convection. 


\section{Collision of equatorially-trapped waves}

In addition to synoptic observations, we examine the severe flooding event of January 2011 by looking at convectively coupled equatorially-trapped waves, namely Kelvin waves, and intraseasonal oscillations such as the MaddenJulian Oscillation (MJO) [10]. Both these waves play critical roles in the Australasia region with effects extending poleward from their equatorial path. First, we look at these waves with the technique of wavenumber-frequency filtering, and then briefly compare the results to previous work on the normal mode analyses of the leading dynamical modes [15].

\subsection{Wavenumber-frequency filtering}

Wheeler and Kiladis [14] described a method of filtering selected frequencies from outgoing long wave radiation (OLR) anomaly data (OLR is a proxy for cloudiness and convection) to identify several types of equatorially trapped waves and the MJO. Figure 3 shows Hovmoller (time-longitude) diagrams for both daily National Center for Environmental Prediction (NCEP) reanalysis OLR data and Mk3L simulation OLR data (covered in section 4) for the period of December 2010 to February 2011. We used the frequency bands from Wheeler and Kiladis [14] for both Kelvin waves (period of 2.5 to 20 days, wavenumbers 1-14) and the MJO (period of 30 to 96 days, wavenumbers 1-5) filtering of the OLR data. The OLR is averaged over $15 \mathrm{~N}-15 \mathrm{~S}$, encompassing the typical areas of tropical convection and paths of the zonally propagating waves. The negative OLR anomalies (blue, enhanced convection) are seen in the Indonesian area (around 120E) for the entire period, and the pattern of supressed (yellow) and enhanced convection typical of the MJO is seen across the Indo-Pacific region. Convectively-coupled Kelvin waves are contoured in green, and the negative phases of the MJO (enhanced convection) are contoured in dashed red. The left plot of Figure 3 shows Kelvin waves colliding with the MJO north of Australia during early to mid January, consistent with the extreme rainfall experienced in mid-January over Australia. 
Figure 3: Time-longitude diagrams of oLR $\left(\mathrm{W} \mathrm{m}^{-2}\right)$ anomalies averaged over $15 \mathrm{~N}-$ 15S covering the period from December 2010 to February 2011 obtained from (left) NCEP reanalysis data, and (right) Mk3L STD-FORCED simulation (see Section 4). Contours show the collision of Kelvin waves (green contour intervals (CI) are at $7 \mathrm{~W} \mathrm{~m}^{-2}$ ) with the areas of enhanced convection associated with the MJO (red dashed CI are at $10 \mathrm{~W} \mathrm{~m}^{-2}$ ).
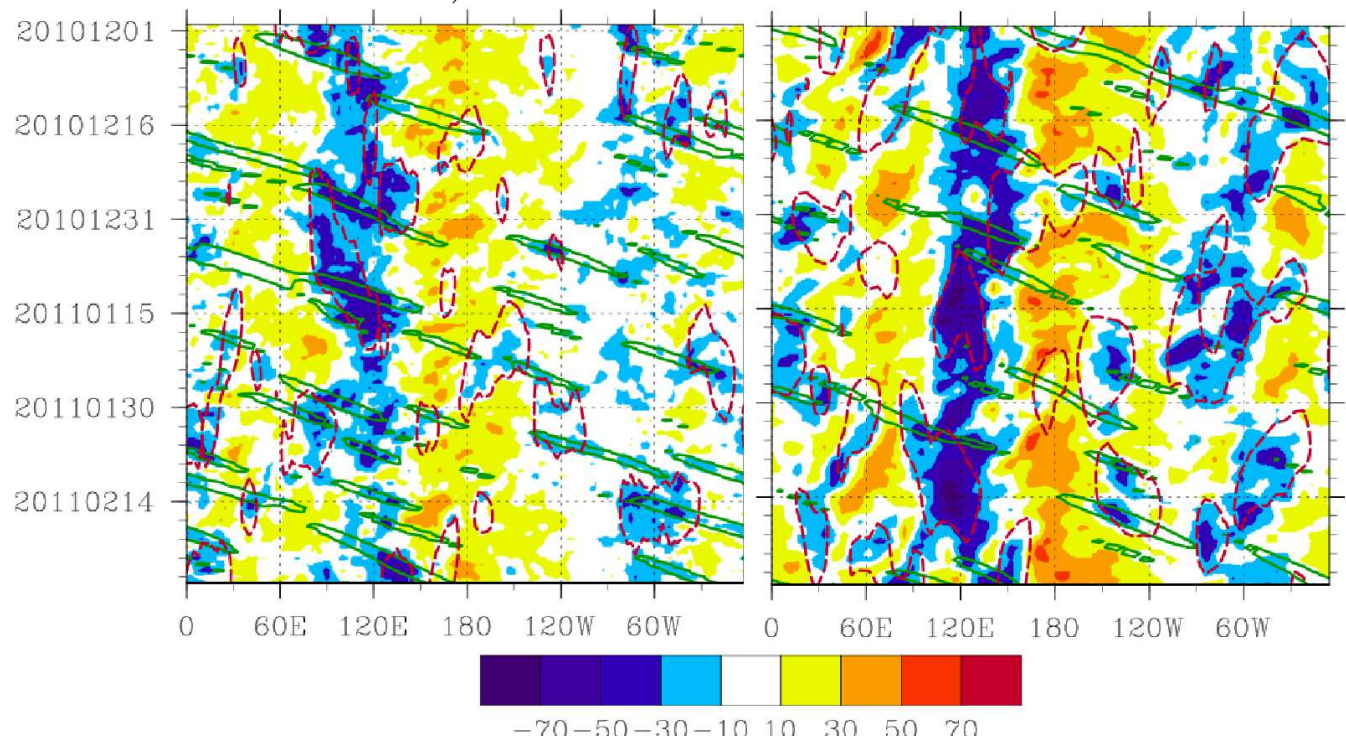

\subsection{Dynamical Modes}

The wave extraction results agree with previously published work on the changes in the growth and structures of leading dynamical modes during January 2011 [15] using a two-level linearized primitive equation model [5]. Changes in the growth and structures of leading dynamical modes were shown to have a role in climate regime changes $[6,7]$ and some strong El Niño events [8]. There were several classes of unusually fast-growing modes during the study period. Kelvin waves, seen colliding with the MJO in Figure 3, show an explosive growth rate with a period $\mathrm{T}=18.4$ days and an e-folding time (inverse growth rate) of $\tau=4.2$ days; this is nearly three times shorter than 
the inverse growth rate of the leading Kelvin wave for the January 1979 basic state studied by Frederiksen [3, 4, for more details]. Also found by Whelan et al. [15] were a group of fast-growing intraseasonal oscillation modes with periods between 40 and 50 days (consistent with the period of the MJO), e-folding times between 5.8 and 6.8 days, and flow fields consistent with the extreme flooding during January 2011.

Storm track modes, typically the fastest growing modes, as well as slowgrowing cyclogenesis modes, crossed south-eastern Australia once again (they moved south of Australia during the El Niño period of 1997-2006, extending to 2009). The fastest growing storm track mode in the southern hemisphere had a disturbance streamfunction with a large amplitude across south-eastern Australia. Leading monsoonal modes were associated with the instability characteristics of quasi-stationary disturbances over Australia at the time. Whelan et al. [15] presented figures illustrating these leading modes. Together, the two techniques, wavenumber-frequency filtering and dynamical analyses, give a thorough picture of the nature of the several unusally strong classes of modes that were active over Australia during the extreme flooding. The position, collisions and extraordinary growth rates of modes discussed by Whelan et al. [15] agree with and complement the synoptic analysis. Our ensemble simulation results are presented in the next section.

\section{$4 \quad$ Mk3L ensemble simulations}

The CSIRO Mk3L is a computationally efficient spectral general circulation model suited to climate variability studies [12]. In this study, we ran the stand-alone Mk3L atmospheric model which consists of atmosphere, land surface and sea ice components. The atmosphere component includes a cumulus convection scheme coupled to a prognostic stratiform cloud scheme. The radiation scheme calculates shortwave and longwave radiation separately every two hours to accommodate both annual and diurnal cycles. Clear-sky radiation calculations are performed at each timestep for the calculation of 
cloud radiative forcings. The sea ice component is a multi-layer dynamicthermodynamic sea ice model which describes ice in three layers (one for snow and two for ice) and allows fractional ice cover at sea ice gridpoints. Mk3L uses an 18 level hybrid vertical coordinate system with a horizontal resolution of R21, corresponding to a $5.625^{\circ}$ zonal and $3.18^{\circ}$ degree meridional resolution, and a timestep of 20 minutes. Mk3L employs a semi-implicit leapfrog scheme with a Robert-Asselin time filter to prevent decoupling at odd and even timesteps [12]. We modified the stand-alone atmospheric Mk3L to be forced by the observed monthly mean HADISST dataset as well as time-evolving $\mathrm{CO}_{2}$ [2]. HADISST data $\left(1^{\circ} \times 1^{\circ}\right)$ was interpolated onto the Mk3L grid both spatially and temporally (per timestep).

Eight ensemble members (hereafter referred to as FORCED) plus a baseline (STD-FORCED) were run for the period 1870-2011, forced with the timeevolving $\mathrm{CO}_{2}$ and SST data. The STD-FORCED run used the Mk3L default initial conditions (provided in a default restart file, the result of a 100 year spin-up run to bring the model to equilibrium for pre-industrial conditions) paired with the time-evolving $\mathrm{CO}_{2}$ and interpolated HADISST data. Each ensemble member was initialized with perturbed atmospheric fields of pressure, streamfunction, velocity potential and temperature to obtain the new restart file

$$
\mathrm{NRF}=\mathrm{DRF} \pm(\mathrm{DRF}-\mathrm{FRF}) \times 0.1 .
$$

Here DRF is the default restart file, and FRF is one of four restart files taken from different years of a control simulation run for 145 years with constant preindustrial boundary conditions of climatological SSTs and $\mathrm{CO}_{2}$ concentrations fixed at $280 \mathrm{ppm}$. We substituted the daily thermodynamic sea ice model values of the STD-FORCED simulation into each member simulation of the FORCED ensemble to reduce variation between members.

Figure 4 shows both the NCEP reanalysis OLR anomaly data and the STDFORCED OLR anomalies for January 2011 from the Mk3L model, and they show good agreement. Figure 5 shows the precipitation for January 2010 for both the NCEP reanalysis and the STD-FORCED simulation, again with good agreement. We find a large variation in the timing and areas of anomalous 
Figure 4: OLR anomalies for January 2011 from (top) NCEP reanalysis data and (bottom) STD-FORCED Mk3L simulation.
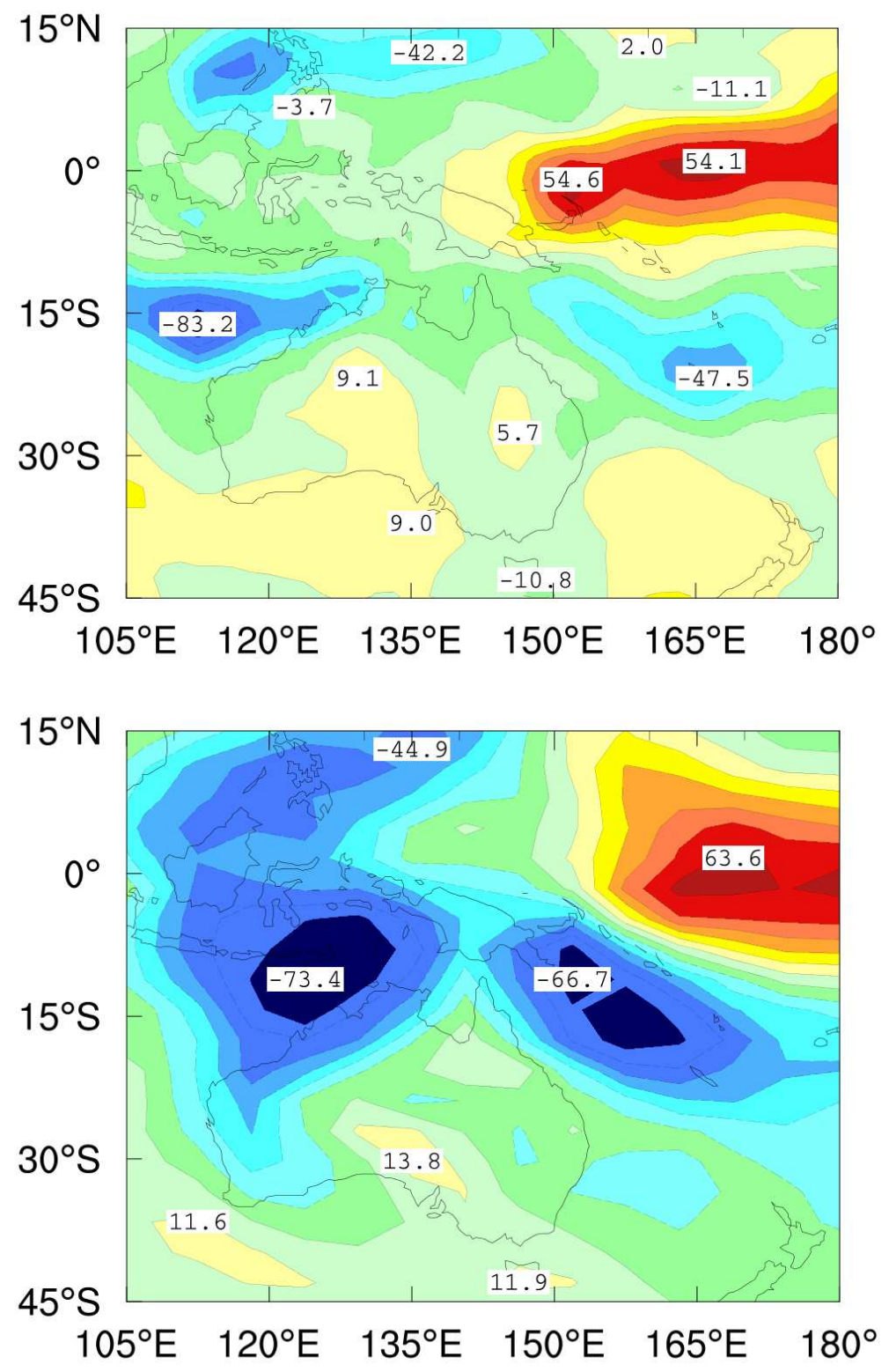
Figure 5: Precipitation for January 2011 from (top) NCEP reanalysis and (bottom) STD-FORCED simulation.
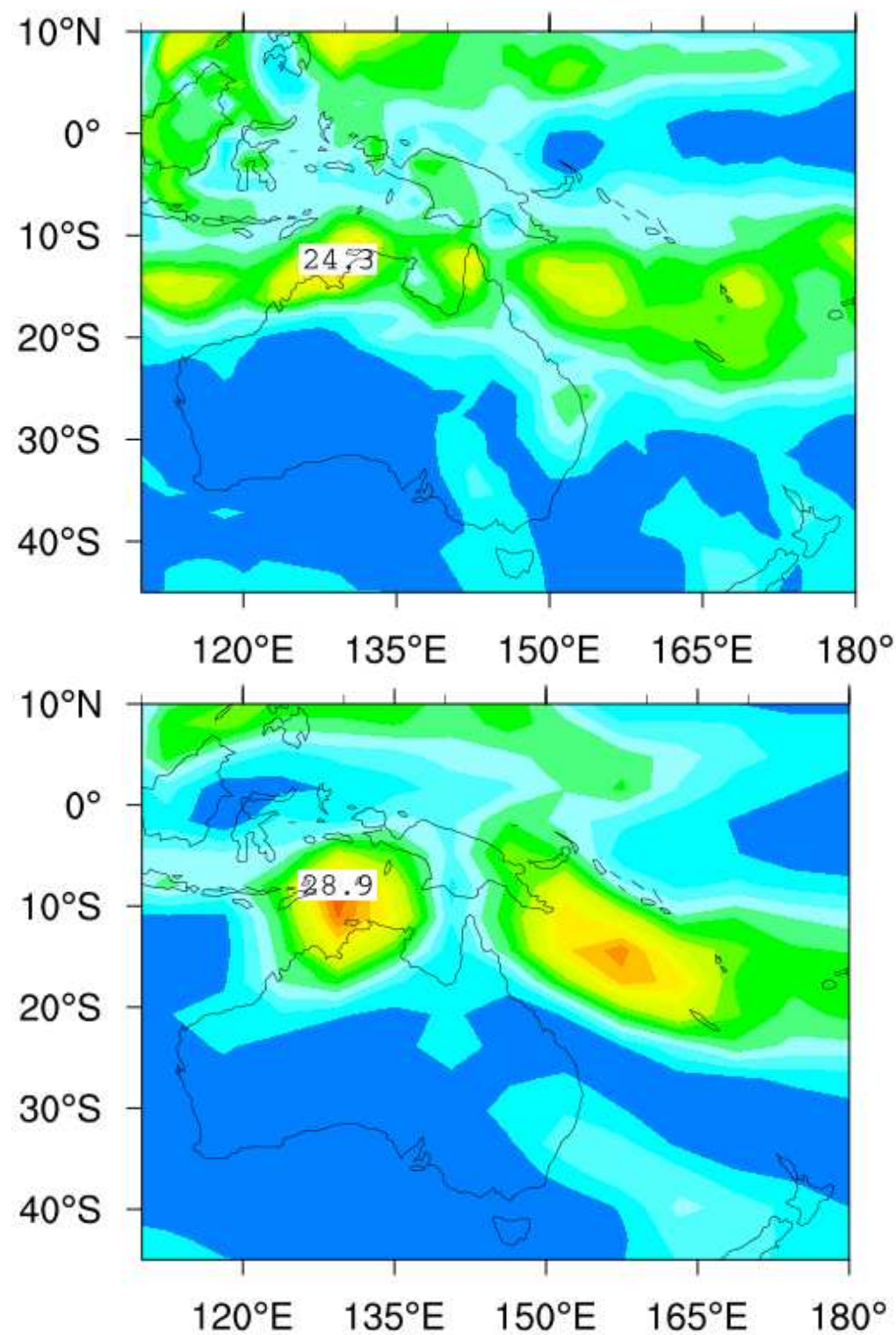
Figure 6: Precipitation for January 2011, FORCED ensemble variance.

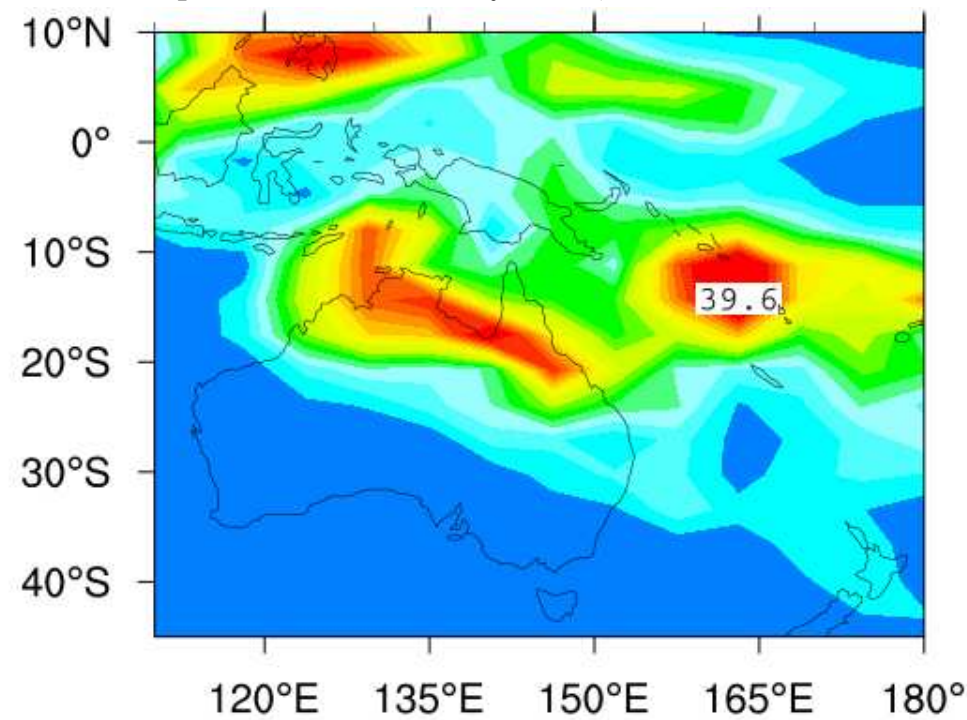

precipitation between the ensemble members, as shown in the ensemble variation in Figure 6. All members displayed anomalous precipitation near northern Australia during the late December to early February time period, but a few members located the highest precipitation offshore. Wavenumberfrequency filtering of the ensemble simulations also showed variation in the timing of the Kelvin waves and enhanced phases of convection, with some members missing a collision (not shown). The Kelvin wave and MJO collision occurs in the Mk3L STD-FORCED simulation, but is seen in late January (Figure 3). This variability underscores the nature of severe weather events relying on the particular timing of multiple elements to produce the highest impacts. 


\section{Conclusions}

We offer dynamical analyses of the extreme flooding event over northern and eastern Australia in January 2011. Significant intraseasonal oscillation and Kelvin wave activity constructively interfered on the critical days of extreme rainfall. We find that Mk3L simulations and both the timing and patterns of the dynamical modes are consistent with the synoptic situation seen in observations. The analyses in this article offer novel insights into the factors behind this severe flooding event.

\section{References}

[1] Australian Bureau of Meteorology. Record-breaking La Niña events: An analysis of the La Niña life cycle and the impacts and significance of the 2010-11 and 2011-12 La Niña events in Australia. July 2012. http: //www.bom.gov.au/climate/enso/history/La-Nina-2010-12.pdf C182

[2] C. Deser, A. S. Phillips, and M. A. Alexander. Twentieth century tropical sea surface temperature trends revisited. Geophys. Res. Lett., 37:L10701, 2010. doi:doi:10.1029/2010GL043321. C187

[3] J. S. Frederiksen. Genesis of intraseasonal oscillations and equatorial waves. J. Atmos. Sci., 59:2761-2781, 2002. doi:10.1175/1520-0469(2002)059<2761:GOIOAE > 2.0.CO;2. C186

[4] J. S. Frederiksen and C. S. Frederiksen. Monsoon disturbances, intraseasonal oscillations, teleconnection patterns, blocking and storm tracks of the global atmosphere during January 1979: Linear theory. $J$. Atmos. Sci., 50:1349-1372, 1993. doi:10.1175/1520-0469(1993)050<1349:MDIOTP > 2.0.CO;2 C186 
[5] J. S. Frederiksen and C. S. Frederiksen. Role of dynamical modes in changing southern hemisphere climate. ANZIAM J., 52:C56-72, 2010. http://journal.austms.org.au/ojs/index.php/ANZIAMJ/article/ view/3892 C185

[6] J. S. Frederiksen and C. S. Frederiksen. Decadal changes in Southern Hemisphere winter cyclogenesis. CSIRO Marine and Atmospheric Research Paper No. 002, 2005. http:

//www.cmar.csiro.au/e-print/open/frederiksenjs_2005b.pdf C185

[7] J. S. Frederiksen and C. S. Frederiksen. Interdecadal changes in southern hemisphere winter storm track modes. Tellus, 59A:599-617, 2007. doi:10.1111/j.1600-0870.2007.00264.x. C185

[8] J. S. Frederiksen and C. S. Frederiksen. Twentieth century winter changes in Southern Hemisphere synoptic weather modes. Adv. Meteor., 2011:353829, 2011. doi:10.1155/2011/353829. C180, C185

[9] D. A. Jones, W. Wang, and R. Fawcett. High-quality spatial climate data-sets for Australia. Aust. Meteor. Ocean. J., 58:233-248, 2009. http://www.bom.gov.au/amoj/docs/2009/jones_hres.pdf C182, C183

[10] R. A. Madden and P. R. Julian. Observations of the 40-50 day tropical oscillation-A review. Mon. Wea. Rev., 122:814-837, 1994. doi:10.1175/1520-0493(1994)122<0814:OOTDTO>2.0.CO;2 C184

[11] S. G. Philander (Ed.). El Niño, La Niña, and the southern oscillation. Academic Press, 1990. https://www.elsevier.com/books/ el-nino-la-nina-and-the-southern-oscillation/holton/ 978-0-12-553235-8 C180

[12] S. J. Phipps, L. D. Rotstayn, H. B. Gordon, J. L. Roberts, A. C. Hirst, and W. F. Budd. The CSIRO Mk3L Climate System Model version 
1.0-Part 1: Description and evaluation. Geosci. Model Develop., 4:483-509, 2011. doi:10.5194/gmd-4-483-2011 C186, C187

[13] G. Wang, and H. H. Hendon. Sensitivity of Australian rainfall to inter-El Niño vaiations. J. Climate, 20:4211-4226, 2007. doi:10.1175/JCLI4228.1 C180

[14] M. Wheeler and G. N. Kiladis. Convectively coupled equatorial waves: analysis of clouds and temperatures in the wavenumber-frequency domain. J. Atmos. Sci., 56:374-398, 1999. doi:10.1175/1520-0469(1999)056<0374:CCEWAO>2.0.CO;2 C184

[15] J. A. Whelan, J. S. Frederiksen, C. S. Frederiksen, and S. L. Osbrough. Synoptic and dynamical analyses of ENSO extreme events over Australia. MODSIM2013, 20th International Congress on Modelling and Simulation. Modelling and Simulation Society of Australia and New Zealand, December 2013, 2590-2596.

www.mssanz.org.au/modsim2013/L7/whelan.pdf C180, C181, C184, C185, C186

\section{Author addresses}

1. J. Whelan, CSIRO Oceans and Atmosphere, Aspendale, Victoria 3195, Australia.

mailto: jennifer. whelan@csiro.au

2. J. S. Frederiksen, CSIRO Oceans and Atmosphere, Aspendale, Victoria 3195, Australia.

mailto: jorgen.frederiksen@csiro.au 